\title{
HEINZ MEANS AND TRIANGLES INSCRIBED IN A SEMICIRCLE IN BANACH SPACES
}

\author{
MinA DinARVAND
}

Abstract. In this paper, we introduce two classes of new geometric constants for Banach spaces by using the Heinz means that interpolate between the geometric and arithmetic means. One of these constants is closely related to the modulus of convexity of the space and it seems to represent a useful tool to estimate the exact values of the James and von Neumann-Jordan constants of some Banach spaces, while the study of the other one seems to be more complicated. Moreover, we investigate some geometric properties related to these constants and calculate the precise values of these two constants for several Banach spaces. We also study the stability under norm perturbations of these constants.

Mathematics subject classification (2010): 46B20.

Keywords and phrases: Heinz mean, James constant, modulus of convexity, uniformly non-square Banach space.

\section{REFERENCES}

[1] J. Alonso And E. Llorens-Fuster, Geometric mean and triangles inscribed in a semicircle in Banach spaces, J. Math. Anal. Appl. 340, (2008), 1271-1283.

[2] J. Alonso And P. Martín, A counterexample for a conjecture of G. Zbăganu about the von Neumann-Jordan constant, Rev. Roumaine Math. Pures Appl. 51, 2 (2006), 135-141.

[3] J. Banaś And K. Fra̧CZeK, Deformation of Banach spaces, Comment. Math. Univ. Carolin. 34, 1 (1993), 47-53.

[4] M. Baronti, E. Casini And P. L. PaPini, Triangles inscribed in a semicircle, in Minkowski planes, and in normed spaces, J. Math. Anal. Appl. 252, (2000), 124-146.

[5] J. A. Clarkson, The von Neumann-Jordan constant for the Lebesgue spaces, Ann. of Math. 38, 2 (1937), 114-115.

[6] H. CUI AND G. LU, Hölder's means and triangles inscribed in a semicircle in Banach spaces, Filomat 26, 2 (2012), 371-377.

[7] M. DINARVAND, Hölder's means and absolute normalized norms on $\mathbb{R}^{2}$, Filomat 31, 6 (2017), 1583 1593.

[8] J. GAO, The uniform degree of the unit ball of a Banach space (I), Nanjing Daxue Xuebao 1, (1982), 14-28 (in Chinese, English summary).

[9] J. GAO AND K.-S. LAU, On the geometry of spheres in normed linear spaces, J. Austral. Math. Soc. 48, (1990), 101-112.

[10] K. Goebel And W. A. KiRK, Topics in Metric Fixed Point Theory, Cambridge University Press, Cambridge, 1990.

[11] R. C. JAMES, Uniformly non-square Banach spaces, Ann. of Math. 80, 2 (1964), 542-550.

[12] P. Jordan and J. von Neumann, On inner products in linear metric spaces, Ann. of Math. 36, (1935), 719-723.

[13] M. Kato, L. Maligranda and Y. Takahashi, On James and Jordan-von Neumann constants and the normal structure coefficient of Banach spaces, Studia Math. 144, (2001), 275-295.

[14] N. Komuro, K.-S. SAito And R. TANAKA, On the class of Banach spaces with James constant $\sqrt{2}$, Math. Nachr. 289, (2016), 1005-1020.

[15] J. Lindenstrauss And L. TZafriri, Classical Banach spaces II, Springer-Verlag, Berlin, 1979. 
[16] E. Llorens-Fuster, E. M. Mazcuñán-Navarro And S. Reich, The Ptolemy and Zbăganu constants of normed spaces, Nonlinear Anal. 72, (2010), 3984-3993.

[17] L. Maligranda, N. Petrot And S. Suantai, On the James constant and B-convexity of Cesàro and Cesàro-Orlicz sequence spaces, J. Math. Anal. Appl. 326, (2007), 312-331.

[18] K.-I. Mitani, K.-S. Saito And T. Suzuki, On the calculation of the James constant of Lorentz sequence spaces, J. Math. Anal. Appl. 343, (2008), 310-314.

[19] S. SAeJung, Another look at Cesàro sequence spaces, J. Math. Anal. Appl. 366, (2010), 530-537.

[20] W. Sanhan And S. Suantai, Some geometric properties of Cesàro sequence space, Kyungpook Math. J. 43, 2 (2003), 191-197.

[21] J. S. Shue, On the Cesàro sequence spaces, Tamkang J. Math. 1, (1970), 143-150.

[22] T. Suzuki, A. Yamano And M. Kato, The James constant of 2-dimensional Lorentz sequence spaces, Bull. Kyushu Inst. Technol. Pure Appl. Math. 53 (2006), 15-24.

[23] R. WoLf, A norm inequality related to affine regular hexagons, Beitr. Algebra Geom. 53, (2012), 529-546.

[24] C. YANG AND H. LI, An inequality between Jordan-von Neumann constant and James constant, Appl. Math. Lett. 23, (2010), 277-281.

[25] C. YANG AND H. LI, An inequality on Jordan-von Neumann constant and James constant on $Z_{p, q}$ space, J. Math. Inequal. 7, 1 (2013), 97-102.

[26] C. YANG AND F. WANG, On a new geometric constant related to the von Neumann-Jordan constant, J. Math. Anal. Appl. 324, (2006), 555-565. 